\title{
Web Based Survey of Adult Population of West and Central Saudi Arabia about Cause and Management of Keratoconus
}

\author{
Sultan Alzuhairy' ${ }^{1}$, Raghad Hamza ${ }^{2}$, Moaz Alharbi ${ }^{3}$, Mohammed Alqadi $^{4}$, Atheer Alharthi $^{2}$, \\ Khames Torki Alzahrani' ${ }^{5}$ Ali Hassan Alshehri²
}

${ }^{1}$ Department of Ophthalmology, Qassim University, Buraidah, Saudi Arabia

${ }^{2}$ Medical College, Taif University, Taif, Saudi Arabia

${ }^{3}$ Faculty of Health Sciences, King Abdul Aziz University, Jeddah, Saudi Arabia

${ }^{4}$ Medical College, Najran University, Najran, Saudi Arabia

${ }^{5}$ Ministry of Health, Jeddah, Saudi Arabia

Email: dr.sulzuh@gmail.com

How to cite this paper: Alzuhairy, S., Hamza, R., Alharbi, M., Alqadi, M., Alharthi, A., Alzahrani, K.T. and Alshehri, A.H. (2020) Web Based Survey of Adult Population of West and Central Saudi Arabia about Cause and Management of Keratoconus. Open Journal of Ophthalmology, 10, 341-350.

https://doi.org/10.4236/ojoph.2020.104037

Received: September 24, 2020

Accepted: November 23, 2020

Published: November 26, 2020

Copyright $\odot 2020$ by author(s) and Scientific Research Publishing Inc. This work is licensed under the Creative Commons Attribution International License (CC BY 4.0).

http://creativecommons.org/licenses/by/4.0/

\section{(c) (i) Open Access}

\begin{abstract}
Background: Keratoconus (KC) causes visual disability in young adults. To improve its early detection and compliance, improving the awareness of patients and their relatives is crucial. We present the level of awareness about $\mathrm{KC}$ among the adult population of western Saudi Arabia and its determinants. Methods: This web-based survey was carried out from June to August 2020 in urban and semi-urban areas in western Saudi Arabia. Demographic and eye ailment profiles were collected. To generate responses on the presentation, causes, management and prevention of $\mathrm{KC}$, a five-point Likert scale was used. The logit values were calculated and graded into good and poor awareness. Awareness was associated with other determinants. Results: We surveyed 420 Saudi adults. The median logit score of awareness about KC among participants was 2.86 (inter quartile range (IQR) 0.86; 2.95). The median score of knowledge about the causes and presentation of $\mathrm{KC}$ was 2.86 (IQR $1.1 ; 2.86$ ) and for management, it was 0.00 (IQR $0.00 ; 0.18$ ). The level of awareness was good in 286 participants $(68.1 \%)$ and poor in $134(31.9 \%)$. Residents of major cities $(\mathrm{P}<0.04)$ and women $(\mathrm{P}<0.001)$ had significantly better awareness about KC. Knowledge about KC mainly came from friends and reading about it. The mass media and social media were rarely used to seek knowledge. Conclusions: Awareness about the presentation, causes and management of $\mathrm{KC}$ was good in two-thirds of adults but with some variation. Strategies to involve the community and stress health education need to be urgently implemented. Campaigns should target the male and semi-urban population in western Saudi Arabia.
\end{abstract}




\section{Keywords}

Keratoconus, Public, Saudi Arabia, Awareness

\section{Introduction}

Keratoconus $(\mathrm{KC})$ is an ectatic disease characterized by the mainly bilateral but occasionally unilateral progressive thinning and protrusion of the cornea, resulting in irregular astigmatism and sometimes scarring and thereby leading to significant visual impairment [1]. Worldwide, the annual incidence of $\mathrm{KC}$ ranges from 1 to 50 patients per 100,000 [2] [3]. In Saudi Arabia, regional studies have reviewed the epidemiology of $\mathrm{KC}$ and its management outcomes [4] [5]. In Hail area, it was 4 per 100,000 adult population [4]. In Asir province, it was 20 per 100,000 population [5]. Regional variation of $\mathrm{KC}$ incidence is noted in a large country [6]. The rate of KC in the Saudi population is higher than that reported in other parts of the world [7] [8]. There is wide variation in its modes of management depending on its stage at presentation and the resources available [9] [10] [11]. The inherent pathology and rate of progression also determine the change from non-invasive to surgical management of eyes with KC [12].

High quality eye services are available free of charge to the Saudi population. To further reduce visual disabilities, strategies such as health promotion, local organ donation and improved compliance should be planned. Both service providers and eye patients are stakeholders in this task. KC management includes periodic eye checkups, prescriptions for spectacles and contact lenses, collagen cross-linkage, refractive surgery and keratoplasty [13]. An eye bank at a tertiary eye center in central Saudi Arabia provides donor material for keratoplasty to different institutions.

The western region, one of five regions in Saudi Arabia, has large cities such as Jeddah, Makah and Medina as well as many small but well-developed semi-urban areas. The total population of this region is around 9.5 million. Nearly 187 ophthalmologists provide secondary and tertiary eye care to this population [14].

To the best of our knowledge, there is limited information on awareness among the general Saudi population about KC, which is a disease mainly affecting young adults in their productive life. To provide effective and timely intervention for $\mathrm{KC}$, it is essential to support the population and encourage $\mathrm{KC}$ patients to comply with eye professionals' advice. We discuss the awareness of KC of adults in western Saudi Arabia as well as its prevention and management and the source of their information.

\section{Methods}

The ethical and research committee of our university approved this survey-based cross-sectional study. Given the Covid-19 pandemic, the responses of participants were collected using Google between June and August 2020. Written in- 
formed consent was obtained. Adults aged 18 years and older agreeing to participate were included. They were approached through social media, personal contacts and WhatsApp groups. Those not consenting to participate were requested to leave the survey. Participants were requested to complete all the survey questions. The questionnaire was prepared in the local language. To ensure translation consistency, reverse translation and a pilot of the survey tool was undertaken. The tenets of the Helsinki Declaration were strictly abided by during all stages of the research.

We assumed that the level of awareness among the five million Saudi adults in western KSA was $57 \%$ [15]. To achieve a $95 \%$ confidence interval and $7 \%$ acceptable error margin, with a study design effect of 2, we needed at least 380 participants. To compensate for incomplete responses, we increased the sample by $10 \%$. We used Open Epi software to calculate the sample for this cross-sectional study [16].

Five medical students were involved in the study. They approached the adult population in three major cities and semi-urban areas using social media to encourage them to participate and then sent a link for the web-based questionnaire.

The demographic information collected included age group, sex, occupation, literacy rate and social status. Information on $\mathrm{KC}$ among participants and relatives, other eye medication, surgeries and systemic ailments were collected. Residents of Makkah, Medina and Jeddah were considered urban and the rest were grouped as semi-urban dwellers.

Sixteen questions were related to KC grouped as 1$) \mathrm{KC}$ as a disease (11 questions), 2) treatment of the condition (4) and 3) prevention of KC (1) (Appendix: 1). We had undertaken quality control measures like pilot of the measurement tool, reverse translation, monitoring of the data collection. We also performed Cronbach alpha test $(>0.75)$ to study internal reliability of the questionnaire for awareness. Participants responded using a five-point Likert scale [17]. The scores for correct responses compared with the gold standard (three consultant replies) were awarded as follows: -2.63 for full disagreement, -1.1 for disagreement, 0 for neutral, 0.09 for agreement and 2.83 for full agreement. The logit values of each participant were summed to determine the overall awareness score. This was further graded as good and poor depending on whether the score was $50 \%$ or more of the correct score. The good and poor awareness groups were correlated to different demographic and ocular ailments.

The collected data were entered into a Microsoft Excel spreadsheet. After cleaning the data and undertaking consistency checks, they were transferred into the Statistical Package for Social Studies (SPSS 25) (IBM, NY, USA). Univariate analysis was performed using the parametric method. The continuous outcome variable (logit score of awareness) was plotted to study the distribution. For normally distributed variables, the mean and standard deviation were calculated. For non-normal variables, the median and inter quartile range (IQR) were estimated. The qualitative data were presented as the number and percentage. The comparison of good and poor awareness was associated with the determinants. 
Two-sided P values were calculated for statistical significance. A P value of $<0.05$ was considered statistically significant.

\section{Results}

We surveyed 420 adult residents of western Saudi Arabia. Their profile is given in Table 1. There was an adequate distribution of participants by age group and gender. The proportion of urban participants was more than semi-urban participants. Three forth of the participants were college graduates and employed. The ocular profile of participants is given in Table 2. Nearly one-third were using spectacles for distance viewing. One in eight participants is using contact lenses and a similar proportion had undergone refractive surgery. Nine participants were suffering from $\mathrm{KC}$, representing a prevalence of $2.1 \%$ ( $95 \%$ confidence interval $0.7 ; 3.5)$. Twenty-four $(5.7 \%)$ had a relative who had KC.

The source of their information included friends (42; 9\%), social media (49; $11.7 \%)$, relatives with KC (28;6.7\%), lectures $(14 ; 3.3 \%)$ and reading $(52 ; 12.4 \%)$. The median logit score of awareness about $\mathrm{KC}$ among participants was 2.86 (IQR 0.86; 2.95) Figure 1.

The logit score of three sub-groups of awareness cause and presentation of $\mathrm{KC}$, management and prevention were also analyzed separately. The median logit score of knowledge about cause and presentation of KC among adult population of western Saudi Arabia was 2.86 (IQR 1.1; 2.86). The median logit score of knowledge about management of KC among adult population of western Saudi Arabia was 0.00 (IQR 0.00; 0.18). The median logit score of knowledge about prevention of KC was 0.00 (IQR $0.00 ; 0.00$ )

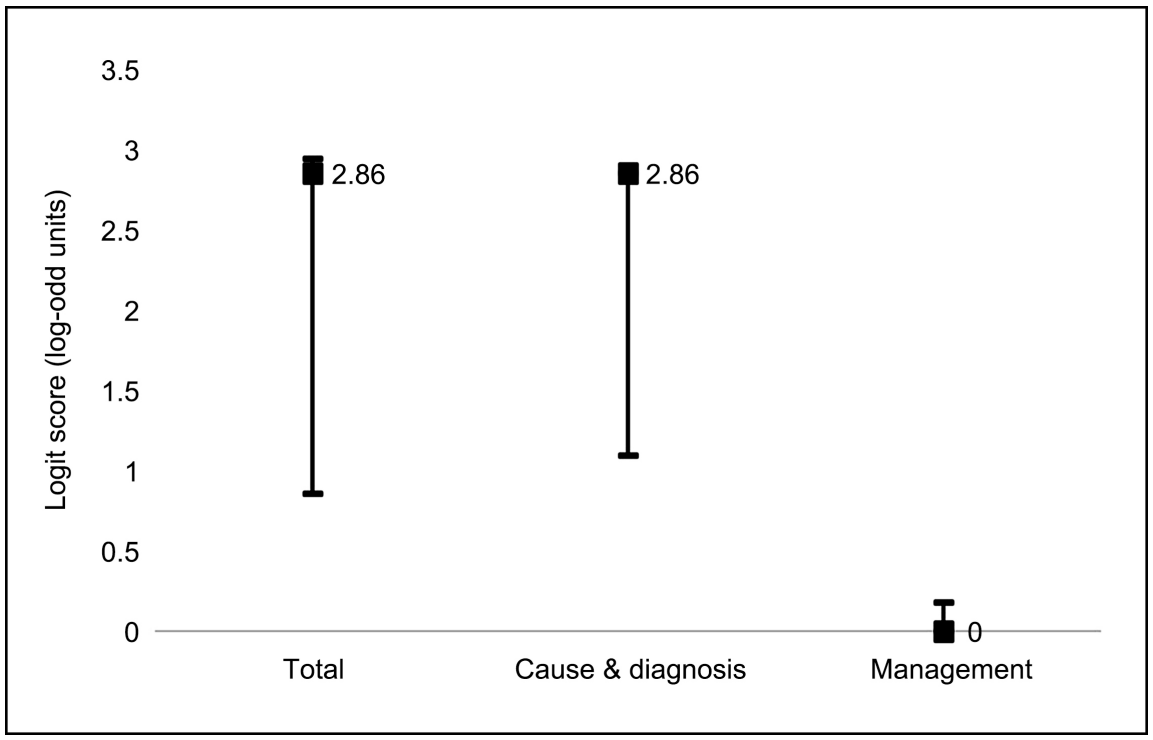

Figure 1. Awareness score of keratoconus among adult population of Western Saudi Arabia. The logit score of all questions related to awareness, logit score of awareness about causes and diagnosis and score about knowledge of management of keratoconus is given in $\mathrm{X}$ axis. Vertical bar shows value of median logit score upper end of bar is $75 \%$ quartile while lower end of the bar depicts $25 \%$ quartile value. 
Table 1. Profile of surveyed adult Saudi population of Western Saudi Arabia for awareness about keratoconus.

\begin{tabular}{|c|c|c|c|}
\hline & & Number & Percentage \\
\hline \multirow{4}{*}{ Age group } & 18 to 25 & 98 & 23.3 \\
\hline & 26 to 30 & 65 & 15.5 \\
\hline & 31 to 40 & 106 & 25.2 \\
\hline & More than 40 & 151 & 36.0 \\
\hline \multirow{2}{*}{ Gender } & Male & 202 & 48.1 \\
\hline & Female & 218 & 51.9 \\
\hline \multirow{6}{*}{ Residence } & Makkah (city) & 39 & 9.3 \\
\hline & Jeddah (city) & 143 & 34.0 \\
\hline & Madina (city) & 34 & 8.1 \\
\hline & Taif (semi-urban) & 114 & 27.1 \\
\hline & Yanbu (semi-urban) & 60 & 14.2 \\
\hline & Khulayas (semi-urban) & 30 & 7.1 \\
\hline \multirow{5}{*}{ Literacy } & Elementary & 2 & 0.5 \\
\hline & Middle school & 3 & 0.7 \\
\hline & High school & 77 & 18.3 \\
\hline & University & 308 & 73.3 \\
\hline & High education & 30 & 7.1 \\
\hline \multirow{5}{*}{ Occupation } & Student & 79 & 18.8 \\
\hline & Employed & 206 & 49.0 \\
\hline & Housewife & 33 & 7.9 \\
\hline & Retired & 66 & 15.7 \\
\hline & Unemployed & 36 & 8.6 \\
\hline \multirow{4}{*}{ Social status } & Married & 255 & 60.7 \\
\hline & Single & 148 & 35.2 \\
\hline & Divorced & 10 & 2.4 \\
\hline & Widow & 7 & 1.7 \\
\hline
\end{tabular}

The level of awareness was good in $286(68.1 \%)$ and poor in poor in 134 (31.9\%) participants. Of the former, only $6(1.4 \%)$ participants had an excellent grade of awareness.

The good and poor grades of awareness of participants were associated with different independent variables (Table 3$)$. Female gender $(\mathrm{P}<0.001)$ and residents of major cities $(\mathrm{P}=0.03)$ were significantly associated to good awareness about KC. 
Table 2. Ocular profile of adult Saudi population of Western Saudi Arabia participating in survey for awareness about keratoconus.

\begin{tabular}{ccc}
\hline & Number & Percentage \\
\hline Using spectacles for distance viewing & 136 & 32.4 \\
Using contact lens for viewing & 55 & 13.1 \\
Refractive surgery done & 51 & 12.1 \\
Eye allergy & 105 & 25 \\
Taking eye medication & 19 & 4.5 \\
Other Eye surgery in past & 16 & 3.8 \\
Systemic health ailment & 96 & 22.9 \\
Diagnosed with keratoconus & 9 & 2.1 \\
Keratoconus in other family member & 24 & 5.7 \\
\hline
\end{tabular}

Table 3. Factors associated with good and poor awareness about keratoconus among surveyed adult population of western Saudi Arabia.

\begin{tabular}{|c|c|c|c|c|c|c|}
\hline \multirow{3}{*}{ Gender } & \multirow[b]{2}{*}{ Male } & \multicolumn{2}{|c|}{$\begin{array}{c}\text { Good awareness of } \\
\text { KC }(n=286)\end{array}$} & \multicolumn{2}{|c|}{$\begin{array}{c}\text { Poor awareness of } \\
\mathrm{KC}(\mathrm{n}=134)\end{array}$} & \multirow{2}{*}{$\begin{array}{c}\text { Validity } \\
\text { OR }=2.2 \\
(95 \% \text { CI } 1.4 ; 3.3)\end{array}$} \\
\hline & & 131 & 45.8 & 87 & 64.9 & \\
\hline & Female & 155 & 54.2 & 47 & 35.1 & $\mathrm{P}<0.001$ \\
\hline \multirow[b]{2}{*}{ Age group } & 18 to 30 & 118 & 41.3 & 45 & 33.6 & $\mathrm{OR}=0.7$ \\
\hline & 31 and more & 168 & 58.7 & 89 & 66.4 & $\begin{array}{c}(95 \% \text { CI } 0.5 ; 1.1) \\
P=0.1\end{array}$ \\
\hline \multirow{2}{*}{ Residence } & Major city & 157 & 54.9 & 59 & 44.0 & $\begin{array}{c}\mathrm{OR}=1.5 \\
(95 \% \mathrm{CI} 1.0: 2.3)\end{array}$ \\
\hline & Semi urban & 129 & 45.1 & 75 & 56.0 & $\begin{array}{c}(95 \% \text { C1 } 1.0 ; 2.3) \\
P=0.04\end{array}$ \\
\hline \multirow{5}{*}{ Occupation } & Students & 51 & 17.8 & 28 & 20.9 & \multirow{5}{*}{$\begin{array}{c}\chi^{2}=0.1 \\
D f=4 \\
P=0.8\end{array}$} \\
\hline & Housewife & 22 & 7.7 & 11 & 8.2 & \\
\hline & Employed & 146 & 51.0 & 60 & 44.8 & \\
\hline & Retired & 43 & 15.0 & 23 & 17.2 & \\
\hline & Unemployed & 24 & 8.4 & 12 & 9.0 & \\
\hline \multirow[t]{2}{*}{ Literacy } & Not school graduates & 58 & 20.3 & 24 & 17.9 & $\begin{array}{c}\mathrm{OR}=0.85 \\
(95 \% \text { CI } 0.5 ; 1.5)\end{array}$ \\
\hline & College \& higher & 228 & 79.7 & 110 & 82.1 & $\mathrm{P}=0.6$ \\
\hline \multirow{2}{*}{ Social status } & Married & 167 & 58.4 & 88 & 65.7 & $\begin{array}{c}\mathrm{OR}=0.7 \\
(95 \% \mathrm{CI} 0.5 .1)\end{array}$ \\
\hline & Not married/single & 119 & 41.6 & 46 & 34.3 & $\begin{array}{c}(95 \% \text { Cl } 0.5 ; 1.1) \\
P=0.2\end{array}$ \\
\hline \multirow{2}{*}{ KC status } & With KC in family & 6 & 2.1 & 3 & 2.2 & $\begin{array}{c}\mathrm{OR}=0.9 \\
\end{array}$ \\
\hline & No KC in family & 280 & 97.9 & 131 & 97.8 & $\begin{array}{c}(95 \% \text { Cl } 0.2 ; 3.8) \\
P=0.9\end{array}$ \\
\hline \multirow[b]{2}{*}{ Eye allergy } & Yes & 67 & 23.4 & 38 & 28.4 & $\mathrm{OR}=0.8$ \\
\hline & No & 219 & 76.6 & 96 & 71.6 & $\begin{array}{c}(95 \% \text { CI } 0.5 ; 1.2) \\
P=0.3\end{array}$ \\
\hline \multirow[b]{2}{*}{ Eye surgery } & Yes & 9 & 3.1 & 7 & 5.2 & $\mathrm{OR}=0.6$ \\
\hline & No & 277 & 96.9 & 127 & 94.8 & $\begin{array}{c}(95 \% \text { CI } 0.2 ; 1.6) \\
P=0.3\end{array}$ \\
\hline
\end{tabular}




\section{Discussion}

The level of awareness about KC was good in two third of the surveyed adult population of Western Saudi Arabia. One in seventeen surveyed participants had $\mathrm{KC}$ in family. Females and residents of the major cities had better awareness about KC compared to males and residents of semi-urban population. The awareness about prevention and management were less compared to the knowledge about causes and presentation. The source of knowledge about KC was mainly through friends and reading about it. Mass media, social media and interaction with health personnel were not the main source of information about KC.

This is perhaps the first such survey in Saudi Arabia inquiring adult Saudi population about keratoconus. There was a good representation of both genders, age groups and urban and semi-urban population. There seems to be a strong need for health education using population preferred mode of delivering these messages. The score system used in the present study for evaluating five graded response seems to be better than qualitative method of describing the responses of participants. This was because there was a wide variation in non-response for individual questions related to awareness.

Two thirds of participants had a good level of awareness about KC in present study. This matched with the level of awareness among non-medical students of Abha province of Saudi Arabia [15]. A study to inquire about blinding eye diseases in Saudi Arabia had an exceptionally low level of awareness among Saudi population [18]. The knowledge about common eye diseases among adult Saudi resident of Riyadh was high [19]. It seems that KC; a less known than other common eye diseases but more prevalent eye ailment in western Saudi Arabia needs more awareness for its early detection, better compliance of the eye professionals' advice.

The rate of $\mathrm{KC}$ in participants of present study and their family was $5.7 \%$. This was close to $4.8 \%$ in pediatric age-group noted in Saudi Arabia [20]. This is much higher than the global incidence documented suggesting more stress on public health approach to deal with visual disabilities due to KC including health promotion.

Health promotion to improve awareness among patients, their relatives and population at large has been advocated in Brazil and then globally by Violet June [21]. This campaign included education for avoiding proven risk factors like frequent and vigorous rubbing of eyelids. It also stresses on two hit theory suggesting genetic factor and rubbing precipitating development of keratoconus [22].

There was wide difference in level of awareness among urban (city dwellers) compared to other participants in present study. This was also noted by Dondana et al. [23] in South India. Even in northern province of Saudi Arabia with less urban population, the level of knowledge about eye diseases was low [24]. The study stresses to have better reach of health promotion campaigns to the popula- 
tion beyond major cities of Saudi Arabia.

In our study, females had better knowledge than males about KC. This was in contrast to the less awareness about blinding eye diseases in females compared to males noted in the developing country like Nepal and Pakistan [25] [26]. The knowledge about hypertension and its health effect was better in Saudi females compared to males [27]. Even the knowledge about dry eye disease and cataract among Jordanian females was better than males [28]. It seems that better education in females of Arab countries has made adult females more conscious about knowledge of important eye diseases.

There were a few limitations in the present study. Use of web-based survey tool during Covid Pandemic perhaps could have resulted in a bias population that was smartphone computer users in the study area. Therefore, extrapolating the study results to the entire population especially adult semi-urban population not well versed with digital knowledge seeking tools should be done with caution.

\section{Acknowledgements}

We thank the people of Saudi Arabia for participating in this survey. We thank Dr Rajiv Khandekar for guiding and giving inputs to improve research.

\section{Conflicts of Interest}

The authors declare no conflicts of interest regarding the publication of this paper.

\section{References}

[1] Hashemi, H., Heydarian, S., Hooshmand, E., Saatchi, M., Yekta, A., Aghamirsalim, M., et al. (2020) The Prevalence and Risk Factors for Keratoconus: A Systematic Review and Meta-Analysis. Cornea, 39, 263-270. https://doi.org/10.1097/ICO.0000000000002150

[2] Gokhale, N.S. (2013) Epidemiology of Keratoconus. Indian Journal of Ophthalmology, 61, 382-383. https://doi.org/10.4103/0301-4738.116054

[3] Assiri, A.A., Yousuf, B.I., Quantock, A.J. and Murphy, P.J. (2005) Incidence and Severity of Keratoconus in Asir Province, Saudi Arabia. British Journal of Ophthalmology, 89, 1403-1406. https://doi.org/10.1136/bjo.2005.074955

[4] AlShammari, Z., AlShammari, R., AlOrf, S., AlShammari, R., AlShammari, W. and Als, W. (2016) Prevalence, Clinical Features and Associated Factors of Keratoconus Patients Attending Ophthalmology Department, King Khalid Hospital, Hail City, Saudi Arabia. EC Ophthalmology, 3, 388-400.

[5] Saini, J.S., Saroha, V., Singh, P., Sukhija, J.S. and Jain, A.K. (2004) Keratoconus in Asian Eyes at a Tertiary Eye Care Facility. Clinical and Experimental Optometry, 87, 97-101. https://doi.org/10.1111/j.1444-0938.2004.tb03155.x

[6] Georgiou, T., Funnell, C.L., Cassels-Brown, A. and O'Conor, R. (2004) Influence of Ethnic Origin on the Incidence of Keratoconus and Associated Atopic Disease in Asians and White Patients. Eye (London, England), 18, 379-383.

https://doi.org/10.1038/sj.eye.6700652 
[7] Pearson, A.R., Soneji, B., Sarvananthan, N. and Sandford-Smith, J.H. (2004) Does Ethnic Origin Influence the Incidence or Severity of Keratoconus? Eye (London, England), 14, 625-628. https://doi.org/10.1038/eye.2000.154

[8] Loukovitis, E., Sfakianakis, K., Syrmakesi, P., et al. (2018) Genetic Aspects of Keratoconus: A Literature Review Exploring Potential Genetic Contributions and Possible Genetic Relationships with Comorbidities. Ophthalmology and Therapy, 7, 263-292. https://doi.org/10.1007/s40123-018-0144-8

[9] Barbara, R., Turnbull, A.M., Malem, A. anderson, D.F., Hossain, P., Konstantopoulos, A. and Barbara, A. (2019) Epidemiology of Keratoconus. In: Barbara, A., Ed., Controversies in the Management of Keratoconus, Springer, Cham, 1-16. https://doi.org/10.1007/978-3-319-98032-4 1

[10] Mandathara, P.S., Stapleton, F.J. and Willcox, M.D.P. (2017) Outcome of Keratoconus Management: Review of the Past 20 Years' Contemporary Treatment Modalities. Eye Contact Lens, 43, 141-154. https://doi.org/10.1097/ICL.0000000000000270

[11] Downie, L.E. and Lindsay, R.G. (2015) Contact Lens Management of Keratoconus. Clinical and Experimental Optometry, 98, 299-311. https://doi.org/10.1111/cxo.12300

[12] Shetty, R., Kaweri, L., Pahuja, N., et al. (2015) Current Review and a Simplified "Five-Point Management Algorithm" for Keratoconus. Indian Journal of Ophthalmology, 63, 46-53. https://doi.org/10.4103/0301-4738.151468

[13] American Academy of Ophthalmology. Eyesmart. Keratoconus; Diagnosis and Treatment. https://www.aao.org/eye-health/diseases/keratoconus-diagnosis

[14] Ministry of Health. Saudi Arabia. Statistical Book 2018. Resources for Health Care in Regions. 35-37.

https://www.moh.gov.sa/en/Ministry/Statistics/book/Documents/ANNUAL-STATI STICAL-BOOK-1438H.pdf

[15] Al-Amri, A.M., Al-Ghamdi, A.S., Al-Khabbaz, F.I., Al-Qallaf, A.A., Siddiqui, J.J., Al-Sadiq, F.A., et al. (2020) Level of Awareness among Non-Medical Students toward Keratoconus, Abha, Saudi Arabia. Saudi Journal for Health Sciences, 9, 7-11. https://doi.org/10.4103/sjhs.sjhs $228 \quad 19$

[16] Dean, A.G., Sullivan, K.M. and Soe, M.M. (2013) OpenEpi: Open Source Epidemiologic Statistics for Public Health, Version. http://www.OpenEpi.com

[17] Awang, Z., Afthanorhan, A. and Mamat, M. (2016) The Likert Scale Analysis Using Parametric Based Structural Equation Modeling (SEM). Computational Methods in Social Sciences, 4, 13.

[18] Shibrayn, M.S., Aljarbou, A.M., Alanazi, Y.A. and Alhaqbani, S.M. (2018) General Awareness and Knowledge about Cataracts, Glaucoma and Diabetic Retinopathy in Saudi Arabia. The Egyptian Journal of Hospital Medicine, 70, 1703-1709. https://doi.org/10.12816/0044690

[19] Al Rashed, W.A., Bin Abdulrahman, A.K., Zarban, A.A., Almasri, M.S., Mirza, A.S. and Khandekar, R. (2017) Public Awareness Regarding Common Eye Diseases among Saudi Adults in Riyadh City: A Quantitative Study. Journal of Ophthalmology, 2017, Article ID: 9080791. https://doi.org/10.1155/2017/9080791

[20] Torres Netto, E.A., Al-Otaibi, W.M., Hafezi, N.L., et al. (2018) Prevalence of Keratoconus in Paediatric Patients in Riyadh, Saudi Arabia. British Journal of Ophthalmology, 102, 1436-1441. https://doi.org/10.1136/bjophthalmol-2017-311391

[21] Ambrósio, R. (2020) Violet June: The Global Keratoconus Awareness Campaign. Ophthalmology and Therapy, 9, 685-688.

https://doi.org/10.1007/s40123-020-00283-5 
[22] McGhee, C.N., Kim, B.Z. and Wilson, P.J. (2015) Contemporary Treatment Paradigms in Keratoconus. Cornea, 34, S16-S23.

https://doi.org/10.1097/ICO.0000000000000504

[23] Dandona, R., Dandona, L., John, R.K., McCarty, C.A. and Rao, G.N. (2001) Awareness of Eye Diseases in an Urban Population in Southern India. Bulletin of the World Health Organization, 79, 96-102.

[24] Al-Lahim, W.A., Al-Ghofaili, R.S., Mirghani, H. and ALBalawi, H. (2018) Evaluation of Awareness and Attitudes towards Common Eye Diseases among the General Population of Northwestern Saudi Arabia. The Egyptian Journal of Hospital Medicine, 70, 1983. https://doi.org/10.12816/0044854

[25] Shrestha, M.K., Guo, C.W., Maharjan, N., Gurung, R. and Ruit, S. (2014) Health Literacy of Common Ocular Diseases in Nepal. BMC Ophthalmology, 14, Article No. 2. https://doi.org/10.1186/1471-2415-14-2

[26] Zhao, M., Gillani, A.H., Amirul Islam, F.M., Ji, W., Hayat, K., Li, Z., et al. (2019) Factors Associated with Knowledge, Attitude and Practices of Common Eye Diseases in General Population: A Multicenter Cross-Sectional Study from Pakistan. International Journal of Environmental Research and Public Health, 16, 1568. https://doi.org/10.3390/ijerph16091568

[27] Saeed, A.A., Al-Hamdan, N.A., Bahnassy, A.A., Abdalla, A.M., Abbas, M.A. and Abuzaid, L.Z. (2011) Prevalence, Awareness, Treatment, and Control of Hypertension among Saudi Adult Population: A National Survey. International Journal of Hypertension, 2011, Article ID: 174135. https://doi.org/10.4061/2011/174135

[28] Haddad, M.F., Bakkar, M.M. and Abdo, N. (2017) Public Awareness of Common Eye Diseases in Jordan. BMC Ophthalmology, 17, Article No. 177.

https://doi.org/10.1186/s12886-017-0575-3 